\title{
MEDIÇÃO DE INDICADORES LOGÍSTICOS EM DUAS OPERAÇÕES DE MONTAGEM ABASTECIDAS POR CADEIAS DE SUPRIMENTOS
}

\section{LOGISTIC INDICATORS MEASUREMENT IN TWO ASSEMBLY OPERATIONS FEEDED BY SUPPLY-CHAINS}

\author{
Thiago Morais Menezes \\ Engenheiro de Produção \\ Universidade do Vale do rio dos Sinos - UNISINOS \\ Programa de Pós-Graduação em Engenharia de Produção e Sistemas - PPGEPS \\ Av. Unisinos 950, 93022-000, São Leopoldo, RS \\ 513591-1166 thiago@imagoconsultoria.com.br \\ Marcelo Giovani Guimarães \\ Engenheiro de Produção \\ Universidade do Vale do rio dos Sinos - UNISINOS \\ Programa de Pós-Graduação em Engenharia de Produção e Sistemas - PPGEPS \\ Av. Unisinos 950, 93022-000, São Leopoldo, RS \\ 513591-1166 guimaraes.m@marisol.com.br
}

\section{Miguel Afonso Sellitto}

Doutor em Engenharia de Produção

Universidade do Vale do rio dos Sinos - UNISINOS 
Programa de Pós-Graduação em Engenharia de Produção e Sistemas - PPGEPS

Av. Unisinos 950, 93022-000, São Leopoldo, RS

51 3591-1166 sellitto@unisinos.br

\title{
RESUMO
}

Este artigo apresenta uma metodologia para medição de indicadores logísticos aplicada a dois casos, a montagem de uma manufatura calçadista e o atendimento de pedidos de uma montadora de condicionadores de ar. Ambas são abastecidas por cadeias de suprimentos. O estudo da montagem pode ser útil para sincronização da cadeia e redução de variabilidades na entrada de pedidos, por pulmão de montagem. A metodologia emprega análises quantitativas e gráficas e calcula tempo de atravessamento, inventário, desempenho, pulmão e ocupação da cadeia. O primeiro caso testou e robusteceu a parte quantitativa do método. O segundo caso, composto por montagem padronizada de componentes entregues por cadeia de suprimentos e execução de serviços customizados, foi analisado quantitativa e graficamente e discutidas as implicações do uso do método. Usando os indicadores calculados, sugeriram-se redução de estoque na montagem padronizada e aumento na customização, o que permite reduzir o tempo de atravessamento total.

Palavras-chave: Indicadores Logísticos, Filas em manufatura, Controle de manufatura, Gestão de Cadeia de Suprimentos, Variabilidade em Cadeias de Suprimentos.

\begin{abstract}
This paper presents a methodology for the measurement of logistic indicators. The methodology was applied in two cases: a shoewear assembling manufacture and a air conditioning assembling operation, both feeded by supply-chains. The study of the assembling operation can be useful in synchronizing the supply-chain and reducing variability in order arrivals by forming an assembly buffer. The methodology applies quantitative and graphic analysis to evaluate leadtime, inventory, performance and buffer. The first case was an exploration of the model, testing and refine its quantitative part. The second case, more extended, studied, in quantitative and graphically modes, two serial processes: standard assembling of items delivered by a supply-chain and customized services. The case was discussed and the implications analyzed. With the so calculated indicators, we suggest inventory reduction in assembling and increase in customization, so the total leadtime can also be reduced.
\end{abstract}

Key words:, Logistic indicators, Queues in manufacture, Manufacturing Control; Variability in Supply Chains, Supply Chain management. 


\section{INTRODUÇÃO}

Aumentos na rapidez e na confiabilidade de entregas têm sido considerados como objetivos de estratégias de produção em empresas de montagem de manufaturados ou de bens de base tecnológica. Para alcançar estes objetivos, empresas de manufatura têm julgado importante formar e operar cadeias logísticas integradas e estruturadas para a prestação de serviços e fornecimento de materiais às operações de montagem. É pela logística de suprimentos que a montadora pode responder rapidamente a demandas de difícil previsão, integrando e sincronizando os processos de encomenda e recebimento de itens com a entrega de produtos e serviços aos clientes. $\mathrm{O}$ ambiente de competição tem determinado exigências de desempenho. Se o ambiente mudar, as empresas tentam se adaptar e buscar outro ponto de equilíbrio dinâmico, nem sempre possível e dificilmente previsível.

Segundo Ching (1999), empresas de manufatura podem ser mais competitivas se operarem com cadeias logísticas integradas de suprimentos. Andrade e Furtado (2005) chamam esta prática de externalização da manufatura. Não cabe à manufatura a fabricação de partes, mas a gestão dos resultados, enfocando esforços mais nas competências principais do negócio. Ao confiar as atividades de fabricação e submontagem a fornecedores, a manufatura reconhece a importância da função compras e a conecta à estratégia de fabricação (KRAUSE, SCANELL e CALANTONE, 2000; KRAUSE, PAGELL e CURKOVIC, 2001).

A externalização também é observada em cenário mundial. Ferdows (1997) afirma que uma cadeia de suprimentos pode comprar itens em outras nações, segundo escolhas que consideram custos, competências e diferenças nas políticas locais. Para cadeias de longo alcance, aplica-se o que Chung (1999) chama de competição baseada no tempo (TBC - timebased competition), na qual a redução de tempos é parte da estratégia de competição. Para Stalk e Hout (1990), TBC é mais do que atender datas devidas; é gerenciar o tempo como um recurso produtivo único e limitado, identificando e reduzindo atividades de longa duração. A análise dos tempos em cadeia de suprimentos pode interessar em uma estratégia de competição que vise a aumentar a velocidade e a confiabilidade de entregas.

O objetivo geral deste artigo é mensurar quantitativamente, por indicadores logísticos de desempenho, duas operações de montagem: uma de manufaturados calçadistas, outra de condicionadores de ambientes, os Fan-Coil. Os objetivos secundários são: definir os indicadores logísticos que podem ser empregados am tais casos e revisar seus métodos de cálculo; explorar o método no primeiro caso; e estudar mais profundamente o segundo caso, 
incluindo recomendações de gestão na cadeia de suprimentos.

Ambas as operações são abastecidas por cadeias de prestadores de serviço e fornecedores de itens. Para sincronizar as cadeias e oferecer previsões mais acuradas aos membros, analisou-se a operação final, a montagem, por indicadores logísticos: tempo de atravessamento, inventário em processo, desempenho e pulmão. A análise se vale de modelos já propostos na literatura, tais como o modelo do funil, em Wiendahl (1995) e Plossl (1986), e o diagrama de resultados da teoria das filas, em Kleinrock (1975) e Hillier e Lieberman (1988). O método de pesquisa é o estudo de caso. Análise similares surgem em Bof, Sellitto e Borchardt (2003); Teixeira; Sellitto e Ribeiro (2004); Teixeira, Menezes e Sellitto (2004) e Rosa, Menezes e Cercato (2004). A fundamentação teórica completa surge em Sellitto (2005).

O restante do artigo está organizado em: (i) revisão acerca de cadeia de suprimentos e cálculo dos indicadores; (ii) método de trabalho; (iii) apresentação dos casos; e (iv) conclusões e continuidade de pesquisa. São delimitações de pesquisa: (i) operação de montagem; e (ii) uso dos modelos citados. A extensão a outras operações e a obtenção de indicadores combinados para outras partes da cadeia é remetida à continuidade.

\section{CADEIAS DE SUPRIMENTOS EM OPERAÇÕES INDUSTRIAIS}

Uma cadeia de suprimentos (Supply Chain ou SC) é um conjunto de atividades e de empresas que as desempenhem, transformando matérias-primas em produtos acabados e serviços demandados por clientes finais. A SC forma uma rede de organizações que operam diferentes processos e atividades e produzem valor em forma de produtos e serviços para o consumidor final. É uma seqüência de processos e fluxos que acontecem dentro e entre estágios da cadeia, agindo juntos no atendimento de pedidos de clientes. A SC opera em fases físicas e em ciclos de informação: começa com o consumidor, do qual se extrai a previsão de demanda; passa pelos fornecedores e pela manufatura; e volta ao consumidor, com as entregas e os serviços associados ao produto. Eventualmente, o retorno de itens não consumidos ou descartados fecha o ciclo, em uma operação de logística reversa. O formato da SC faz pensar no negócio como um todo contínuo e sistêmico, no qual um cliente pode ter vários fornecedores e servir a vários consumidores que, por sua vez, podem se abastecer de vários fornecedores, em atividades coordenadas por uma inteligência central (DAVIS, AQUILANO e CHASE, 2001; CHOPRA e MEINDL, 2003; BOWERSOX e CLOSS, 2001; CHRISTOPHER, 2007). 
Em operações de manufatura, a SC tem como função suprir a operação principal, a empresa focal, com materiais específicos, sob encomenda, ou genéricos, para ressuprimento de estoques. Em competição por preço, um dos objetivos da cadeia é executar operações de abastecimento e distribuição pelo menor custo possível. Em competição por velocidade, seu objetivo é dar rapidez e confiabilidade às entregas (BALLOU, 2005).

Arnold (1999) divide a SC em três fases, segundo as transferências de materiais: (i) matérias-primas são recebidas de fabricantes; (ii) são processadas e montadas na manufatura; e (iii) produtos acabados são entregues a clientes. Leite (2003) aponta o retorno de materiais e embalagens como uma cadeia reversa, na qual produtos não vendidos ou sobras voltam para reciclagem, reaproveitamento ou destinação.

O gerenciamento da cadeia de suprimentos (Supply Chain Management ou SCM) é um conjunto de técnicas de gestão utilizadas para alinhar e sincronizar as atividades de produção internas e externas à empresa principal (chamada focal), com o objetivo de reduzir custos, minimizar ciclos de entregas e maximizar o valor percebido pelo cliente final. $\mathrm{O}$ Conselho de Profissionais de Gestão de Cadeias de Suprimentos - Council of Supply Chains Management Professionals define o SCM como o planejamento e a gestão das atividades envolvidas na busca e fornecimento de matérias-primas, coordenação e colaboração com parceiros e canais intermediários e de distribuição (CSCMP, 2006).

O SCM exige um conjunto de processos de negócios que ultrapassa as atividades logísticas típicas, consideradas isoladamente. A integração de processos vai desde as atividades de desenvolvimento de novos produtos, passa pelo marketing, chega a fornecimentos, fabricação, montagem e operações logísticas para executar as operações e inclui a gestão financeira do empreendimento. O SCM requer um esforço sincronizado desde o fornecedor do fornecedor até o cliente do cliente, para a entrega de um produto na hora certa e com o menor custo final e aprimora os níveis de eficiência e de competitividade de toda a cadeia, segundo o impacto que cada elo tem sobre a diminuição de custos e a ampliação do valor agregado ao consumidor final (BOWERSOX, COOPER e CLOSS, 2006).

Algumas vezes, o SCM rompe barreiras entre áreas da empresa focal e entre empresas. Em essência, a SCM integra a gestão do suprimento e da demanda ao longo de diversas empresas, sendo uma função de integração entre processos de negócios, não apenas logísticos e de manufatura, mas também financeiros, comerciais e informacionais entre os membros da cadeia. Algumas funções geralmente encontradas em SCM são: serviços ao cliente, comunicação de distribuição, previsão de vendas, controle de estoques, 
processamento de pedidos, manuseio de materiais e mercadorias devolvidas, peças de reposição, serviços de suporte, estudos de localização de facilidades, compras, embalagens, recuperação e descarte de sucata, transporte e armazenagem (CSCMP, 2006). Para Bowersox e Cooper (1992), a noção básica do SCM é a crença de que a competitividade pode ser aumentada pelo compartilhamento de informações e planejamento e pela operação conjunta entre diversas empresas. Para Davis, Aquilano e Chase (2001), competir com foco no SCM é saber operar com fornecedores, especificar e receber materiais e componentes com qualidade, prazos e preços exigidos pelo cenário de competição.

O SCM pode reduzir os custos de transação, aqueles custos não associados a processos de produção, mas que surgem quando duas organizações decidem operar juntas. Custos de transação surgem devidos a dificuldades de contratação, negociações e salvaguardas contratuais, renegociações de entregas e redirecionamento de ativos mal comprados ou mal especificados. Tais custos surgem por características típicas das transações, tais como a especificidade de ativos, que impede uso alternativo ou incerteza quanto à confiabilidade dos parceiros. Quanto mais transações, mais confiança mútua, caracterizando a cadeia de suprimentos como redutora dos custos de transação (ZYLBERSZTAIN, 2000).

Entende-se que a cadeia de suprimentos é um arranjo interorganizacional capaz de reduzir os custos de transação, pois, devido à repetição, reduz a necessidade de negociações e aumenta a confiança mútua. A cooperação e interação reduzem os riscos individuais e aumenta a eficiência do processo logístico, eliminando duplicidades e desperdícios.

\section{INDICADORES DE OPERAÇÕES LOGÍSTICAS}

Dentre os parâmetros que podem descrever uma operação industrial inserida em uma SC, cinco interessam para este artigo: tempo de atravessamento, inventário em processo, desempenho, pulmão e ocupação. Estes parâmetros foram chamados de indicadores logísticos.

O termo tempo de atravessamento (leadtime) surge na literatura associado, ao menos, a duas grandezas: (i) em um sistema de estoques, é o tempo decorrido entre a detecção de uma necessidade de material e sua chegada; e (ii) em manufatura, é o tempo decorrido entre a chegada dos materiais necessários a uma ordem de fabricação e a conclusão da ordem e sua disponibilização para embarque ao cliente. Para este artigo, interessa a segunda aplicação.

Tubino (1999) define tempo de atravessamento como o tempo que um sistema produtivo gasta para transformar matérias-primas em produtos acabados. Wiendahl (1995) 
distingüe tempo real de atravessamento, probabilístico, utilizado na função controle, e tempo de atravessamento planejado, determinístico, utilizado na função planejamento e em sistemas MRP. O primeiro é medido após a operação. O segundo é calculado antes da operação. Sellitto (2005) define: (i) tempo de atravessamento de ordem de fabricação é o tempo transcorrido entre a liberação, para a manufatura, dos materiais constantes da ordem até a conclusão da última operação; e (ii) tempo de atravessamento da operação é o tempo necessário para a conclusão de cada uma das operações constantes na ordem.

Correa, Gianesi e Caon. (1999) definem inventário em processo como acúmulos de materiais entre fases de um processo de transformação. $O$ inventário em processo cria independência entre as fases: uma eventual interrupção no fluxo de materiais não causa uma parada nas etapas seguintes. Como há variabilidades no abastecimento e nas transferências internas, para que uma operação não resulte desabastecida, antecipam-se entregas e criam-se inventários protetivos. Quando o inventário é superior à necessidade de proteção, incorre-se em custos desnecessários de guarda, o que torna importante conhecer a variabilidade nas transferências e ter um modo de calcular a proteção necessária para compensá-la.

Dois outros indicadores são o desempenho e o pulmão. Desempenho é a quantidade de unidades de valor que a operação produz por unidade de tempo e é medido em toneladas por hora, peças por dia, etc. Pulmão é a quantidade mínima de inventário que mantém a operação abastecida, apesar das variabilidades de entrada e de serviço, compensando eventuais faltas e atrasos em chegadas. É a proteção já mencionada que deve se localizar à frente da operação (SELLITTO, 2005).

Por fim, a ocupação ou utilização de capacidade é o percentual de tempo em que o recurso produtivo está ocupado. No restante do tempo, por variabilidade, o recurso fica ocioso. Em cadeias como as analisadas neste artigo, a ocupação é dada pelo cociente entre a taxa de entrada e a capacidade de saída. Para equilíbrio, a ocupação deve ser menor do que um: do contrário, no longo termo, surge fila infinita (DAVIS, AQUILANO e CHASE, 2001).

\subsection{Cálculo dos indicadores logísticos}

A seguir apresenta-se o método de cálculo dos indicadores que foi usado neste artigo. Inicia-se pelo tempo de atravessamento.

Heinemeyer (apud WIENDAHL, 1995) separa em componentes o tempo de atravessamento. Na Figura 1, o tempo de atravessamento de uma operação em um centro de 
trabalho inicia após o final do processamento no centro de trabalho anterior $(t P E U)$ e termina após o final do processamento do centro de trabalho atual $(t P E)$. Sendo conhecidas as datas, os componentes do tempo de atravessamento podem ser medidos. O tempo de atravessamento simples $(T L)$ de uma operação é calculado pela equação 1. A soma de todos os tempos de atravessamento de operações constantes do roteiro de fabricação da ordem compõe o tempo de atravessamento simples da ordem $(T L s)$.

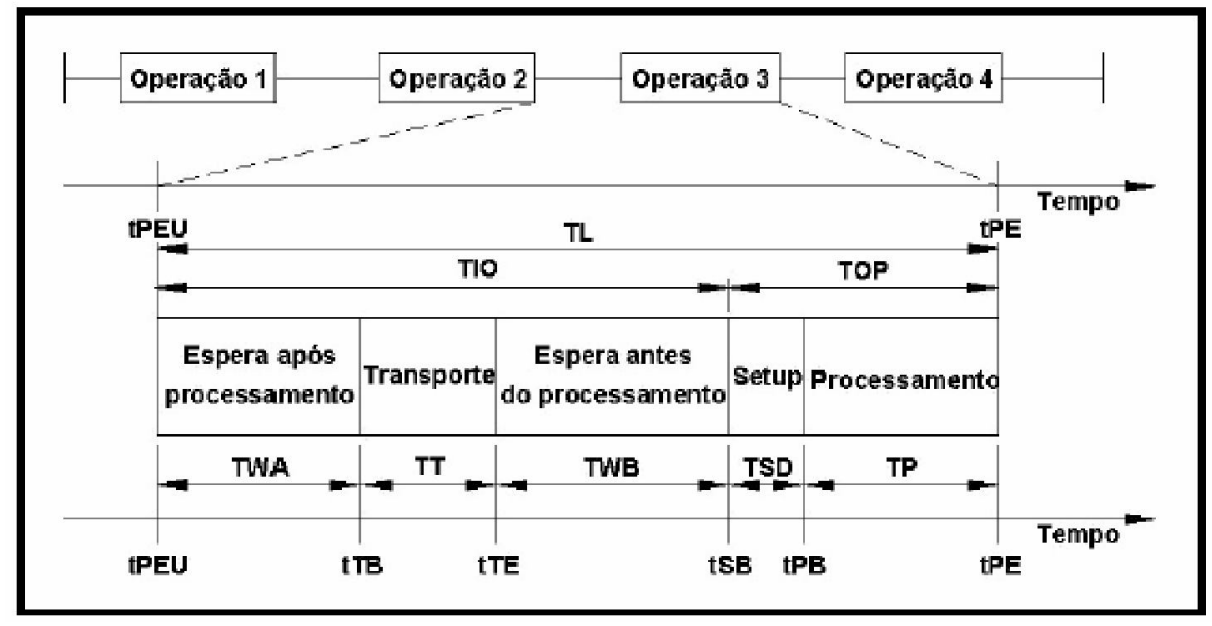

Figura 1: Tempo de atravessamento e elemento de resultado simples

Fonte: Adaptado de Wiendhal (1995, p.53)

$$
T L=t_{P E}-t_{P E U}
$$

na qual:

$t_{P E U}=$ fim do processamento no centro de trabalho anterior; $\mathrm{e}$ $t_{P E}=$ fim do processamento no centro de trabalho em estudo.

O tempo de atravessamento pode ser ponderado pelo esforço de produção. Para a ponderação, Sellitto (2005) usa a quantidade de peças da ordem. O significado físico do tempo de atravessamento ponderado é o valor esperado para o tempo que uma unidade de valor isolada (uma tonelada, uma peça, etc.) leva para atravessar a operação. O tempo de atravessamento ponderado por quantidade médio de uma operação é obtido pela equação 2 . $\mathrm{O}$ desvio-padrão deste tempo é dado pela equação 3 (WIENDAHL, 1995). 


$$
T L_{m w q}=\frac{\sum_{i=1}^{n} T L_{i} \cdot Q_{i}}{\sum_{i=1}^{n} Q_{i}}
$$

$$
T L_{s w q}=\sqrt{\frac{\sum_{i=1}^{n}\left(T L_{m w}-T L_{i}\right)^{2} \cdot Q_{i}}{\sum_{i=1}^{n} Q_{i}}}
$$

nas quais:

$T L_{m w q}=$ tempo de atravessamento médio ponderado por peça;

$T L_{i}=$ tempo de atravessamento total da ordem $i ;$

$Q_{i}=$ quantidade de peças da ordem $i$; e

$T L_{s w q}=$ desvio-padrão do tempo de atravessamento ponderado por peça.

Os indicadores de inventário e de desempenho são calculados após o cálculo do tempo de atravessamento. Interessa operar com valores médios. Para obter o desempenho médio de uma operação, divide-se o total de peças entregues pelo intervalo de tempo entre a primeira e a última entrega (SELLITTO, 2005). O tempo de atravessamento, inventário e desempenho médios se relacionam como na equação 4, a fórmula do funil (WIENDAHL, 1995; WIENDAHL e BREITHAUPT, 2000).

$$
I_{m}=\left[\frac{\Delta Q}{t_{n}-t_{1}}\right] \cdot T L_{m w}=P_{m} \cdot T L_{m w}
$$

na qual:

$I_{m}=$ inventário médio;

$P_{m}=$ desempenho médio;

$\Delta Q=$ total de quantidades despachadas em $n$ ordens; e

$t_{n}$ e $t_{1}=$ datas em que as ordens $n$ e 1 foram encerradas. 
É possível verificar os cálculos de tempo de atravessamento e inventário construindo o diagrama de resultados (throughput diagram) da Figura 2. Para tanto, anotam-se as datas de entrada e saída e as quantidades das ordens. Em intervalos fixos (por exemplo, um dia), somam-se as quantidades que já entraram e as que já saíram e registram-se em gráfico de acumulação, como na figura. As distâncias vertical e horizontal entre os traçados, em $t$, são o inventário instantâneo e o tempo de atravessamento esperado para uma ordem que entre na manufatura em $t$. Se os traçados se aproximam, o inventário diminuiu. Caso se afastem, o inventário cresceu. Caso não se encontrem, não houve interrupção. Na situação ideal, os traçados são paralelos e a distância é curta, indicando equilíbrio e inventário mínimo. Com equilíbrio, pode-se definir valores constantes para o inventário e o tempo de atravessamento da operação, iguais às médias das grandezas no período (WIENDAHL, 1995).

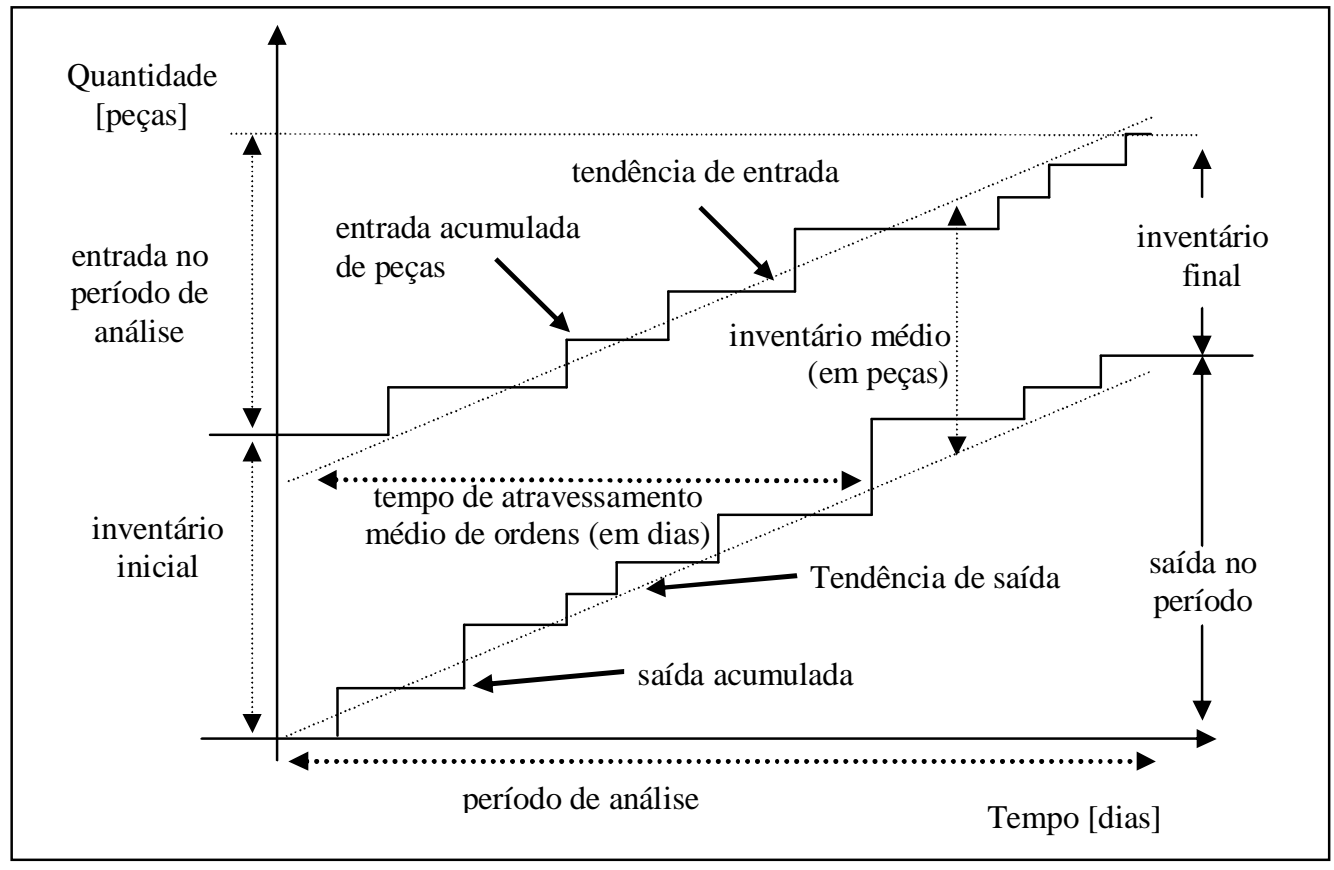

Figura 2: Diagrama de Resultados

Fonte: autores

Sellitto (2005) apresenta e explora um método alternativo para a verificação do cálculo do inventário. Divide-se o período de referência $P$ em intervalos $\Delta t$ e calcula-se, ao fim de cada intervalo, o total de peças que já entraram e saíram da manufatura. A diferença é o inventário instantâneo ao fim do intervalo. Um indicativo para o inventário médio é a média dos inventários nos fins dos intervalos $\Delta t_{i}$ ao longo de $P$, dado pela equação 5 . 


$$
I_{m}=\frac{\sum_{i=1}^{n}\left[I E_{\text {acum }_{i}}-I S_{\text {acum }_{i}}\right]}{n}
$$

na qual:

$I_{m}=$ inventário médio em $P$;

$I E_{a c u m i}$ e $I S_{a c u m i}=$ inventários acumulados de entrada e de saída ao fim do intervalo $\Delta t_{i}$; e $n=$ número de intervalos $\Delta t$ em que o período $P$ foi dividido.

Para o cálculo do pulmão, usa-se o seguinte procedimento: conhecido o intervalo máximo observado sem chegada de ordens $\Delta t_{m a ́ x}$, protege-se a manufatura com um pulmão $B_{m}$ capaz de garantir um resultado médio $P_{m}$, segundo a equação 6 (SELLITTO, 2005).

$$
B_{m}=P_{m} \cdot \Delta t_{\text {máx }}
$$

O objetivo de se calcular e manter um pulmão é evitar ociosidade na operação, que pode ser expressa pelo último parâmetro de interesse, a ocupação dos recursos de manufatura. Uma ocupação satisfatória deve ser próxima a $100 \%$ e pode ser calculada pela equação de Pollaczek e Kinchin (equação 7). A equação exige chegadas markovianas das ordens à manufatura, ou seja, os intervalos de tempo entre chegadas são independentes, identicamente distribuídos e seguem distribuições exponenciais e permite que os tempos de serviço sigam qualquer distribuição (HILLIER e LIEBERMAN, 1988).

$$
N s=\frac{\left[\lambda^{2} \cdot \sigma^{2}+\rho^{2}\right]}{[2 .(1-\rho)]}+\rho
$$

na qual:

$N_{s}=$ número de clientes no sistema de filas, no caso, inventário em número de peças;

$\lambda=$ taxa média de entrada de peças no sistema, em peças por dia;

$\sigma=$ desvio-padrão da saída da manufatura; e

$\rho=$ ocupação do sistema $=$ taxa de entrada média $/$ saída média da manufatura $=\lambda / \mu$. 


\section{A PESQUISA: MÉTODO DE TRABALHO E RESULTADOS}

O objetivo de pesquisa é calcular os seguintes indicadores logísticos em duas operações de montagem abastecidas por cadeias de suprimentos: (i) $T L_{m w q}$ (tempo de atravessamento médio ponderado por quantidade): é o tempo médio de entrega de uma peça; (ii) variabilidade do tempo de atravessamento de peças: $c v=\sigma / \mu$; (iii) desempenho: é a taxa média de saída de peças no intervalo; (iv) intervalo entre saídas: é o tempo médio entre duas saídas de ordens; (v) inventário médio: é a quantidade média de material que já entrou e ainda não saiu da operação; (vi) pulmão: é o inventário mínimo que previne variabilidades; e (vii) ocupação. A técnica de pesquisa foi o estudo de caso exploratório.

O estudo de caso descreve um fenômeno que, se repetido, pode gerar uma teoria. A essência de um estudo de caso é a análise intensa de uma unidade de estudo, que pode ser um indivíduo ou um grupo de indivíduos, que não separa o fenômeno observado de seu ambiente (YIN, 2001). Segundo Eckstein (1975, apud ROESCH, 1999), há cinco modos com que um estudo de caso pode contribuir para uma teoria: (i) oferecer, para posteriores estudos, uma descrição profunda e específica de um objeto; (ii) interpretar eventuais regularidades como evidências de postulados teóricos ainda não enunciados; (iii) criar uma situação para testar uma idéia; (iv) sondar plausivelmente uma teoria proposta pelo terceiro modo; e (v) o caso crucial, que apóia ou refuta a teoria. Entende-se que a contribuição do presente estudo de caso é do terceiro tipo, uma situação construída para o teste de uma idéia.

O método de trabalho foi: seleção das empresas focais e entrevistas com os gestores de cadeia, definição dos recortes de cadeia a analisar, coleta dos dados e análise pelo modelo; e discussão do segundo caso. O primeiro caso exemplifica e robustece a aplicação do método. Apenas o segundo caso, por ser mais rico e envolver duas operações em série, será discutido. Da discussão, espera-se extrair implicações do uso do modelo para o controle da cadeia.

\subsection{O primeiro caso}

O primeiro caso foi estudado em uma empresa que monta calçados infantis e opera em três sedes, distantes mais de cem quilômetros entre si. A capacidade total do arranjo produtivo pode chegar a 16.000 pares diários.

A manufatura de calçados é um processo intensivo em mão-de-obra: corte, costura, pré-fabricação, montagem e acabamento. $\mathrm{O}$ corte recebe matérias-primas, moldes e navalhas 
de fornecedores. Na costura, as peças são unidas por colagem ou costura. Na pré-fabricação, ocorre a fabricação e acabamentos em solas, saltos e palmilhas. Na montagem, o cabedal é montado sobre a fôrma e a sola é colada. No acabamento ocorrem operações como a escovação, limpeza, colocação de produtos auxiliares para embalagem, inspeção final e embalagem em caixa individual e coletiva. Corte, costura e pré-fabricação ocorrem interna e externamente, em ateliers, e são abastecidos por fornecedores de materiais e ferramentas, formando uma rede de operações interorganizacionais, sincronizadas pela montagem.

Para o caso, foram coletados dados de cento e quarenta e sete ordens de fabricação, em uma das montagens da empresa, em dezessete dias, de 14 a 31 de maio de 2007. O sistema de informações não aponta a hora de entrada e saída, portanto, para ordens que entraram e saíram no mesmo dia, adotou-se $T L_{s}=0,5$ dia.

O $T L_{m w q}$ é obtido pela equação 2 e alcança 4,84 dias. Este é o tempo esperado para que um par de calçados atravesse a montagem. O $c v$ usa o desvio-padrão (equação 3) e alcança 0,88 ; o desempenho é a taxa de saída, 875 pares por dia; o intervalo entre saídas é o recíproco do desempenho; o inventário médio alcança 4.232 pares, calculados pela equação 5; o pulmão usa o maior intervalo de tempo entre entradas, um dia; e, como as taxas de entrada e de saída são iguais, a ocupação da montagem é unitária e o seu cálculo não requer a equação 11. Em dezessete dias, entraram e saíram 14.868 pares para montagem (taxa de entrada = taxa de saída $=875$ pares por dia). Há entradas em todos os dias. Para o cálculo do pulmão, foi considerado um intervalo de proteção de um dia. Portanto, o pulmão é a capacidade de despacho da montagem em um dia, ou sejam, 875 pares. Como o inventário médio é de 4.232 pares, há excesso de proteção na montagem.

Os indicadores calculados são sintetizados na Tabela 1.

Tabela 1: Indicadores logísticos da montagem calçadista

\begin{tabular}{rcl}
\hline Indicador & Valor calculado & Dimensão \\
\hline TLmwq $=$ & 4,84 & dias \\
$c v$ TLmwq $=$ & 0,88 & adimensional \\
desempenho $=$ & 875 & pares/dia \\
intervalo entre saídas $=$ & 0,001143 & dias/par \\
inventário médio $=$ & 4.232 & pares \\
pulmão médio $=$ & 875 & dias \\
ocupação $=$ & 1 & adimensional \\
\hline
\end{tabular}




\subsection{O segundo caso}

A operação faz parte de um conglomerado internacional com atuação em mais de 170 países e investimentos anuais, em pesquisa e desenvolvimento, ao redor de 1,8 bilhões de dólares. A empresa opera com uma linha de produtos de base tecnológica, que inclui desde equipamentos de refrigeração de prédios comerciais até produtos de condicionamento de ar residenciais. A empresa apóia ações de colaboração entre membros da cadeia de suprimentos, envolvendo a montagem e os fornecedores de insumos básicos e serviços.

A linha selecionada é a de condicionadores de ar FAN COIL ITC, com capacidade de 3 TR (Toneladas de Refrigeração). Trata-se de um climatizador configurável: as características variam segundo o cliente. A operação ocorre em duas etapas: (i) montagem padronizada, com tempo-padrão de cinco horas; e (ii) serviços específicos do pedido. $\mathrm{O}$ processo segue as etapas da Figura 3. A cadeia de suprimentos é acionada na terceira etapa, pelo $M R P$. O recebimento dos materiais da cadeia dispara a operação estudada, a partir da quarta etapa. O maior tempo de fornecimento, quinze dias, é do motor elétrico.

Coletaram-se informações das ordens de vendas (OV) atendidas entre 09 de abril de 2005 e 21 de outubro de 2005. As atividades foram anotadas em dois grupos: (i) operação de montagem, doravante chamada de produção; e (ii) customizaçao e inspeção pelo cliente, doravante chamados de faturamento.

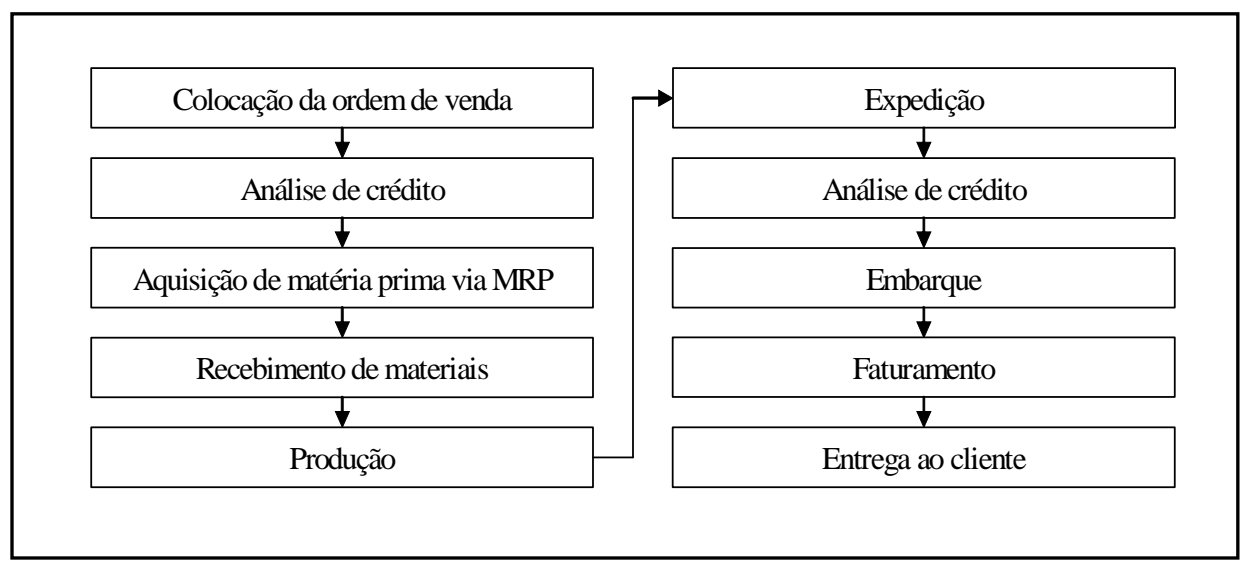

Figura 3: Seqüência de etapas do processo

Fonte: empresa estudada 
Em 195 dias, entraram na cadeia, pela produção, 159 fan-coils, que saíram, pelo faturamento, em 196 dias (taxa de entrada = 0,815, taxa de saída = 0,811 fan-coils por dia, em equilíbrio). Pelas equações do modelo, calcularam-se os tempos de atravessamento médios, desempenhos e inventários médios. Os indicadores calculados são sintetizados na Tabela 2.

Os maiores intervalos de tempo entre entradas são: doze dias (ordens 64.764 e 70.480) para a produção e onze dias (ordens 73.368 e 74.103) para o faturamento. A proteção requerida para a produção é de $B_{m}=[12 \cdot 0,77]=9,24$ unidades e para o faturamento é de $B_{m}=$ $[11.0,81]=8,91$ unidades. O sistema de informações não separa tempos de fila e de processamento de ordens, portanto não há parâmetro de variabilidade para o tempo de serviço, apenas o de tendência central ( $\mu=1,23$ dias/unidade). Admitindo chegadas markovianas, vale a equação 7. Wiendahl (1995) apresenta casos em manufatura em que a distribuição exponencial se ajustou aos tempos de serviço. Aplicando (7) e admitindo distribuição exponencial ( $\mu=\sigma=1,23$ dias/unidade), chega-se a uma ocupação da cadeia de $\rho=96,8 \%$.

Tabela 2: Indicadores logísticos da operação

\begin{tabular}{|c|c|c|c|c|}
\hline Indicador & Produção & Faturamento & Cadeia & Dimensão \\
\hline$T L m w q=$ & 25,0 & 6,7 & 31,7 & dias \\
\hline$c v T L m w q=$ & 0,24 & 1,83 & 0,41 & adimensional \\
\hline desempenho $=$ & 0,77 & 0,81 & 0,81 & unidades/dia \\
\hline intervalo entre saídas = & 1,30 & 1,23 & 1,23 & dias/unidade \\
\hline inventário médio = & 19,25 & 5,41 & 25,66 & unidades \\
\hline pulmão médio = & 9,24 & 8,91 & & dias \\
\hline ocupação = & & & 0,968 & adimensional \\
\hline
\end{tabular}

$\mathrm{Na}$ Figura 4, colocaram-se juntas as grandezas calculadas na cadeia. O tempo de atravessamento total da cadeia é a soma dos tempos parciais. Os desempenhos das etapas da cadeia permitiram calcular a ocupação. Também é possível observar a situação dos inventários médios e dos requisitos de proteção, os pulmões. Observa-se que é possível baixar o inventário médio na produção e é necessário aumentá-lo no faturamento. Em resumo, é possível que haja má distribuição do inventário, maior na posição de menor variabilidade. 


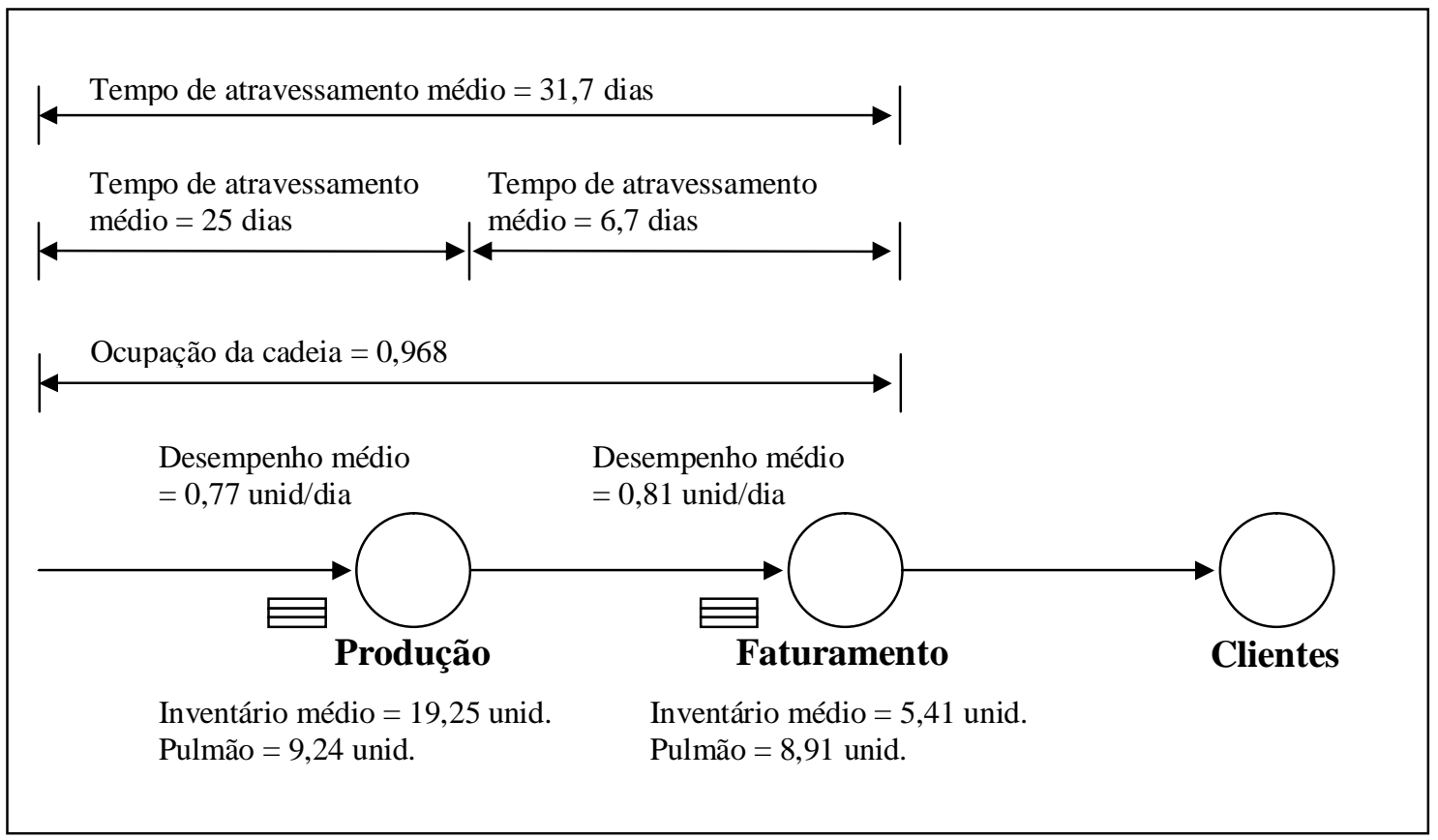

Figura 4: Análise conjunta da cadeia do segundo caso

Fonte: autores

\subsection{Discussão do segundo caso}

Cerca de $75 \%$ do tempo é consumido na produção (coleta de materiais e ferramentas em almoxarifados, análise de desenho, montagem do dispositivo e teste), e o restante no faturamento. Como o tempo-padrão para montar um fan-coil é de 0,5 dia e o tamanho médio de uma ordem é de 1,75 fan-coil, o tempo-padrão médio de uma ordem é de 0,875 dia. Sendo $T L_{m w q}=31,7$ dias, conclui-se que a fila ocupa $[1-0,875 / 31,75]=97,2 \%$ do tempo. Wiendahl (1995) apresenta casos em manufatura mecânica que este percentual vai de $90 \%$ a $98 \%$. Sellitto (2005) apresenta um caso em manufatura calçadista que o percentual supera $80 \%$ e um em manufatura mecânica que supera 92,5\%.

Os dados foram reorganizados e acumulados em intervalos de tempo $\Delta t=5$ dias para o uso de método alternativo de cálculo dos inventários médios e construção do diagrama de resultados. Acumularam-se os volumes de ordens de vendas, de produção e faturamento em função do tempo. Adotaram-se aproximações lineares calculadas pelo método dos mínimos quadrados, conforme a Figura 5, cujos coeficientes de determinação $R^{2}$ são próximos a 1 . O diagrama foi usado para calcular, de modo alternativo, o inventário médio. O cálculo do inventário parece consistente, haja vista a proximidade dos valores obtidos pelos dois 
métodos. A análise gráfica mostra que há, no período, uma pequena tendência de redução de inventário após a produção e antes do faturamento, ou seja, no período, saíram mais pedidos do faturamento que entraram. Os coeficientes angulares das retas (respectivamente $0,821 \mathrm{e}$ 0,837 ) indicam a ordem de grandeza da diferença. Entre a entrada de ordem de venda e a saída da montagem há mais equilíbrio, pois os coeficientes angulares das retas são quase iguais $(0,82)$. Um objetivo de gestão da cadeia de suprimentos pode ser a manutenção do paralelismo entre todas as retas, com a menor aproximação possível, mas sem encontros.

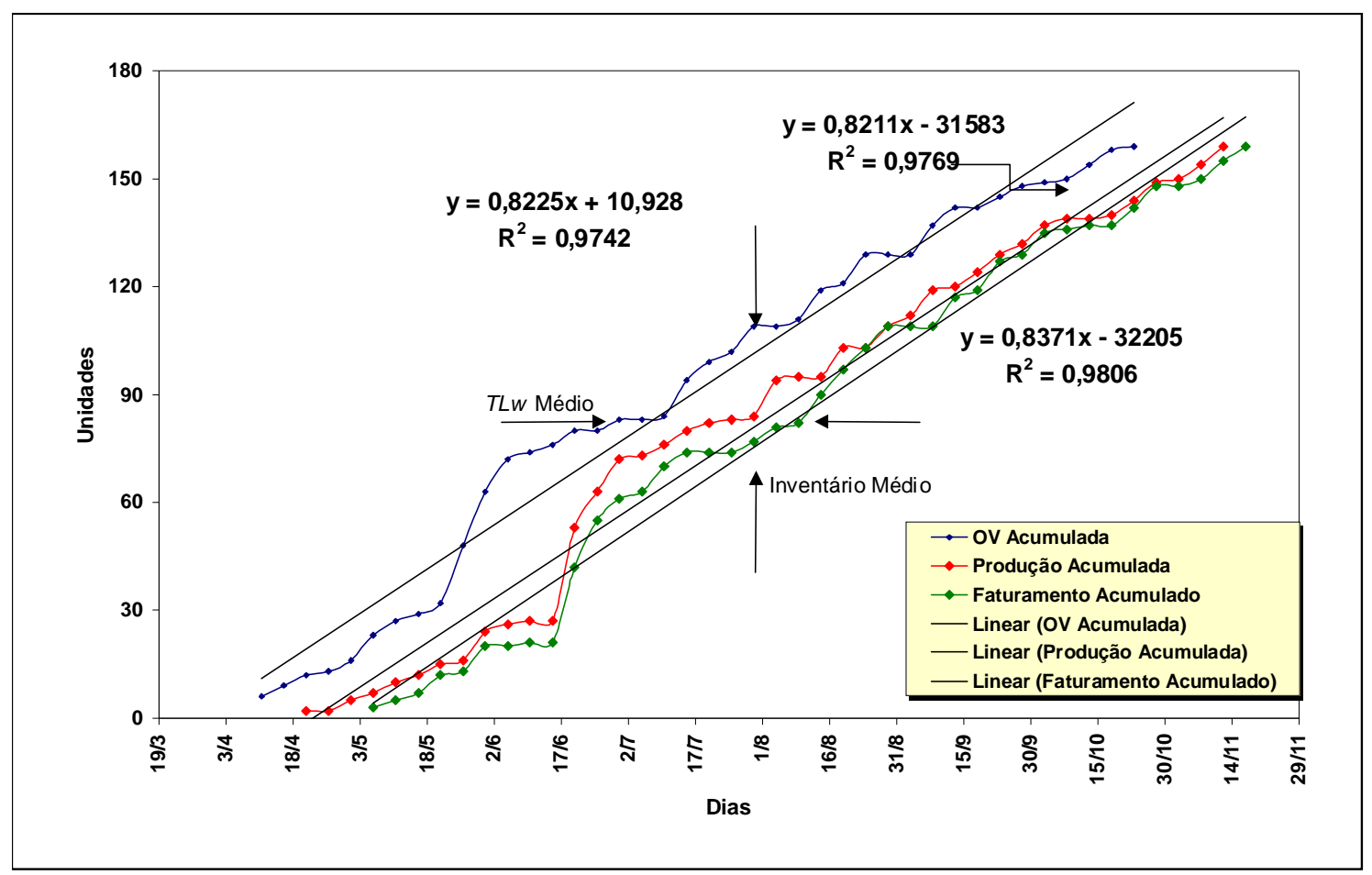

Figura 5: Diagrama de resultados de ordens de vendas, produção e faturamento.

Fonte: autores

Quanto à variabilidade no tempo de atravessamento, a montagem tem um coeficiente de variação mais baixo, 0,24 , do que o serviço, 1,83. Atribui-se esta diferença à natureza intangível do serviço, que o torna menos previsível, e à pouca disponibilidade dos inspetores de clientes, o que retarda a liberação de equipamentos. Ocorre freqüentemente que inspetores deixam acumular serviço, antes de se deslocar até a empresa. Neste momento, o inspetor passa alguns dias em atividades ininterruptas de inspeção, liberando uma grande quantidade de equipamentos em pouco tempo, o que contribui para a variabilidade observada. 
Pouco após 18/5, houve um acréscimo no ritmo de entrada de pedidos, que durou até pouco após $2 / 6$ e se refletiu, a partir de 17/6, na saída de ordens na produção e no faturamento. Este reflexo é um indício de sincronismo nas operações, pois houve resposta ao acréscimo de demanda, defasada de cerca de um mês, como calculado pelo tempo de atravessamento da operação. A produção atingiu seu menor nível de inventário entre 2/7 e 17/7, chegando próximo a dez unidades, mas risco de interrupção, pois as curvas acumuladas de entrada e de saída da produção não se encostam. Pode ser uma boa política reduzir o estoque em processo, pois este parece proteger mais do que exige a variabilidade de entrada. O faturamento parou duas vezes, entre $16 / 8$ e $31 / 8$, e próximo a 31/10. Pode ser uma boa política o aumento de proteção por inventário antes do faturamento, pois a variabilidade no serviço pode estar causando custos com horas-extras, para compensar a eventual ociosidade.

Uma fila média, o pulmão, é desejável para compensar variabilidades. O pulmão foi calculado considerando o maior período sem entrada de pedidos e o desempenho médio. Outro modo de calcular um pulmão é construir um histograma como o da Figura 6, que separa em classes os intervalos entre entradas na produção.

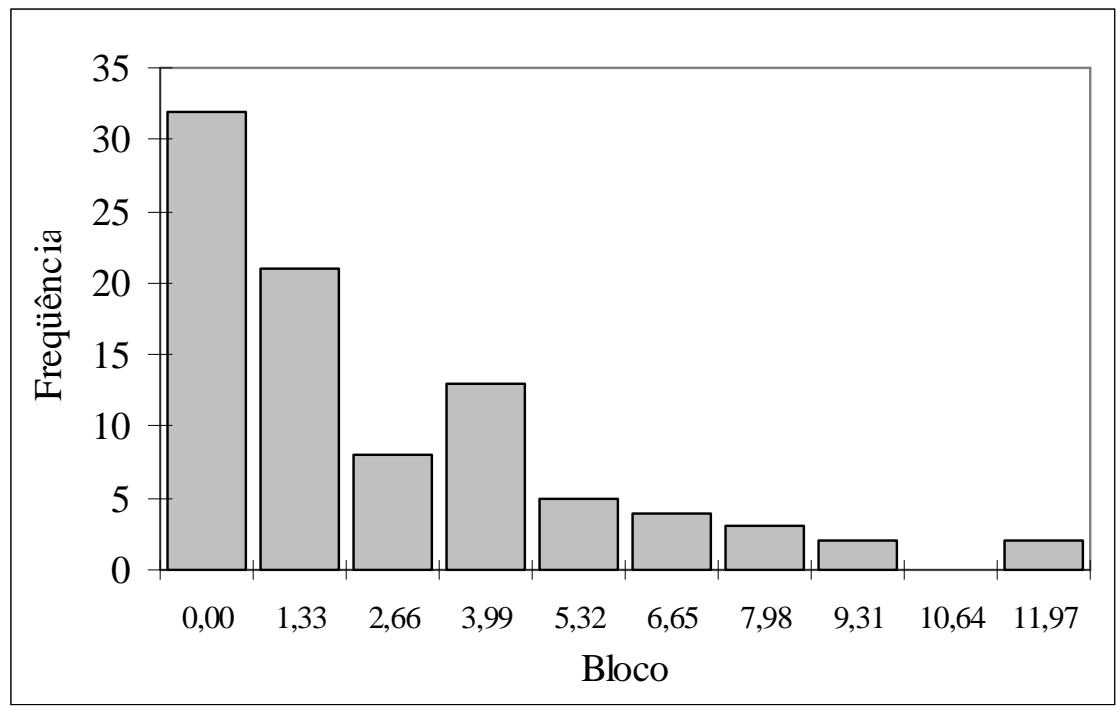

Figura 6: Histograma dos intervalos entre entradas na produção

Fonte: autores

No eixo $x$, aponta-se o valor do início do intervalo de classe e no eixo y o percentual com que cada classe contribui para a distribuição. As duas últimas classes, que se iniciam em 10,64, contribuem com 2,2\% para a distribuição dos intervalos, portanto uma proteção de 
10,64 unidades é eficaz em 97,78\% das vezes. Observa-se que este valor é mais baixo do que o anteriormente calculado, mas não garante proteção para todas as situações de entrada de ordens. Para chegar a uma proteção ótima, são necessários cálculos econômicos que considerem o valor da perda por interrupção da produção em conjunto com o custo de manutenção do pulmão. Tal cálculo é remetido à continuidade de pesquisa.

\section{CONSIDERAÇÕES FINAIS}

O objetivo deste artigo foi apresentar e testar um método para o cálculo de indicadores logísticos em operações de montagem abastecidas por cadeias de suprimentos. Os valores calculados são afetados pela variabilidade na cadeia. Portanto, é possível, pelos indicadores calculados, aferir o desempenho da cadeia, principalmente quanto à variabilidade no abastecimento da montagem. No primeiro caso, a análise apontou proteção excessiva na montagem. No segundo caso, a análise apontou que o inventário em processo pode ser reduzido na produção, mas deve ser aumentado no faturamento, para compensar a variabilidade. Como aumento de inventário implica aumento de custos, uma opção é reduzir a variabilidade no faturamento, de modo a que o atual inventário possa servir como proteção.

Como continuidade de pesquisa, propõe-se incluir fatores econômicos relativos às perdas por interrupção da produção e manutenção do pulmão no cálculo da proteção, otimizando-a. Também propõe-se uma análise das causas das variabilidades na cadeia, que se refletem em variabilidade na chegada de ordens, e a proposição de soluções para reduzir a variabilidade no serviço de faturamento. Esta análise envolverá outros membros da cadeia de suprimentos, pois é nela que surgem as variabilidades que afetam a liberação de ordens. A redução na variabilidade das entradas de OVs permitirá a redução de inventário em processo na linha. Como conseqüência, menores tempos de atravessamento serão alcançados. Também se sugere investigar as implicações do prazo de entrega junto aos clientes. Por fim, pode ser importante estender a abordagem ora testada a mais operações da cadeia, principalmente aos fornecedores imediatos de peças à operação de montagem. Deste modo, pode ser possível obter indicadores combinados. Por exemplo, se duas operações ocorrem em série, o tempo de atravessamento e o inventário combinados pode ser obtido pela soma dos tempos e inventários individuais. Já em operações paralelas, nas quais duas ou mais operações abastecem a mesma montagem, o inventário combinado é a soma dos inventários parciais, mas o tempo de atravessamento combinado é o maior dos dois tempos, pois é o último 
fornecimento que determina o início da próxima operação. Considerações equivalentes podem ser feitas para desempenho.

\section{REFERÊNCIAS}

ANDRADE, C.; FURTADO, J. Discutindo processos de outsourcing da manufatura: uma análise a partir de elementos das indústrias eletrônica, farmacêutica e automobilística. Anais do XXIV Encontro Nacional de Engenharia de Produção - ENEGEP. P. Alegre, 2005.

ARNOLD, J. Administração de materiais. S. Paulo: Atlas, 1999.

BALLOU, R. Gerenciamento da cadeia de suprimentos: planejamento, organização e logística empresarial. P. Alegre: Bookman, 2005.

BOF, L.; SELLITTO, M.; BORCHARDT, M. Medição de tempos de atravessamento e inventário em sistemas produtivos baseados em ordens de fabricação. Anais do XXIV Encontro Nacional de Engenharia de Produção - ENEGEP. Ouro Preto, 2003.

BOWERSOX, D.; CLOSS, D. Logística empresarial: o processo de integração da cadeia de suprimentos. S. Paulo: Atlas, 2001.

BOWERSOX, D.; COOPER, M. Strategic marketing channel management. N. York: McGraw-Hill, 1992.

BOWERSOX, D.; CLOSS, D.; COOPER, M. Gestão logística de cadeias de suprimentos. P. Alegre: Bookman, 2006. 
CHING, H. Gestão de estoques na cadeia de logística integrada: supply-chain. S. Paulo: Atlas, 1999.

CHOPRA, S.; MEINDL, P. Gerenciamento da cadeia de suprimentos: estratégia, planejamento e operação. S. Paulo: Prentice Hall, 2003.

CHRISTOPHER, M. Logística e gerenciamento da cadeia de suprimentos. S. Paulo:

Thomson, 2007.

CHUNG, C. Balancing the Two Dimensions of Time for Time-Based Competition. Journal of Managerial Issues. V.11, n.3, p.299-314, 1999.

CORRÊA, H.; GIANESI, I; CAON, M. Planejamento, programação e controle da produção: MRP II/ERP: conceitos, uso e implantação. S. Paulo: Atlas, 1999.

CSCMP - Council of Supply-Chains Management Professionals. Supply Chain Management/Logistics Management Definitions. Disponível em http://www.cscmp.org/Website/AboutCSCMP/Definitions/Definitions.asp, acesso em 6/2006.

DAVIS, M.; AQUILANO, N.; CHASE, R. 2001. Fundamentos da administração da produção. P. Alegre: Bookman.

FERDOWS, K. Made in the world: the global spread of production. Production and Operations Management. V.6, n.2, p.102-109, 1997.

HILLIER, F.; LIEBERMAN, G. Introdução à pesquisa operacional. R. Janeiro: Campus, 1988. 
KRAUSE, D.; PAGELL, M.; CURKOVIC, S. Toward a measure of competitive priorities for purchasing. Journal of Operations Management. V.19, p.497-512, 2001.

KRAUSE, D.; SCANELL, T.; CALANTONE, R. A structural analysis of the effectiveness of buying firms’ strategies to improve supplier performance. Decision Sciences. V.31, n.1 p.33$55,2000$.

LEITE, P. 2003. Logística reversa: meio ambiente e competitividade. S. Paulo: Prentice Hall.

PLOSSL, G. Production and inventory control. Englewood Cliffs, New Jersey: Prentice Hall. 1985.

ROESCH, S. Projetos de estágio e de pesquisa em administração: guia para estágios, trabalhos de conclusão, dissertações e estudos de caso. S. Paulo: Atlas, 1999.

ROSA, E.; MENEZES, F.; CERCATO, M. Modelagem para o tempo de atravessamento e inventário médio em arranjos produtivos por processo. Anais do XXIV Encontro Nacional de Engenharia de Produção - ENEGEP. Florianópolis, 2004.

SELLITTO, M. 2005. Medição e controle de desempenho estratégico em sistemas de manufatura. Tese de Doutorado em Engenharia de Produção. UFRGS, P. Alegre.

STALK, G.; HOUT, T. Competing against time: how time-based competition is reshaping global markets. N. York: Free Press,1990. 
TEIXEIRA, M.; SELLITTO, M.; RIBEIRO. J. Medição do Tempo de Atravessamento e Inventário em Arranjos Físicos por Processo. Anais da $3^{\text {a }}$ Semana de Engenharia de Produção e Transportes (em CD-Rom), FEENG, P. Alegre, 2003, ISBN 85-88085-17-8.

TEIXEIRA, M.; MENEZES, F. SELLITTO, M. Controle da manufatura: medição do tempo de atravessamento e inventário em arranjos físicos por processo. Anais do XXIV Encontro Nacional de Engenharia de Produção - ENEGEP. Florianópolis, 2004.

TUBINO, D. Sistemas de Produção: a produtividade no chão de fábrica. P. Alegre: Bookman, 1999.

WIENDAHL, H. Load-oriented manufacturing control. Berlim: Springer, 1995.

WIENDAHL, H.; BREITHAUPT, J. Automatic production control applying control theory. International Journal of Production Economics. V.63, p.33-46, 2000.

YIN, R. Estudo de caso: planejamento e método. P. Alegre: Bookman, 2001.

ZYLBERSZTAIN, D. Economia das organizações. In: ZYLBERSZTAIN, D; NEVES, M. (orgs.).Economia e gestão dos negócios agroalimentares. S. Paulo: Pioneira, 2000. 